\title{
Sexual behaviour and morphological variation in the millipede Megaphyllum bosniense (Verhoeff, 1897)
}

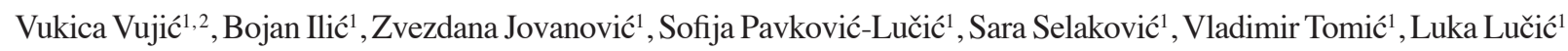 \\ ${ }^{1}$ University of Belgrade, Faculty of Biology, Studentski Trg 16, 11000 Belgrade, Serbia \\ ${ }^{2}$ E-mail:vukica.vujic@bio.bg.ac.rs
}

Keywords: copulation duration, Diplopoda, mating success, morphological traits, sexual behaviour, traditional and geometric morphometrics

\begin{abstract}
Sexual selection can be a major driving force that favours morphological evolution at the intraspecific level. According to the sexual selection theory, morphological variation may accompany non-random mating or fertilization. Here both variation of linear measurements and variation in the shape of certain structures can significantly influence mate choice in different organisms. In the present work, we quantified sexual behaviour of the millipede Megaphyllum bosniense (Verhoeff, $1897)$ as characterized by several sequences. These are: mating latency, duration of copulation, contact to copulation time, duration of contact without copulation, time from entrance (time-point when individuals were placed in boxes in which tests occurred) to contact with copulation, and time from entrance to contact without copulation. Further, we analysed the influence of morphological variation (both variation of linear measurements and variation in the shape of several structures) on mating success. Variation of body length, antennal length, length of the walking legs, trunk width, and trunk height was analysed by traditional morphometrics, while variation in size and shape of the antennae, walking legs, head, and gonopods (promeres, opisthomeres) was analysed using geometric morphometrics. More than half of all physical contacts detected among the millipedes resulted in copulation. Based on the value of sexual selection coefficients, preferences toward the previous partner were found to be prevalent in both female and male choice tests. Individuals with different mating status significantly differed in some morphological traits (body mass, head centroid size, head shape, and promere shape). Our study yielded new information about the sexual behaviour of millipedes and variation of morphological traits as a potential basis for mate preferences.
\end{abstract}

\section{Contents}

Introduction .133

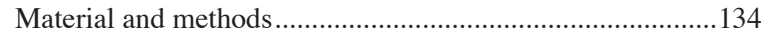

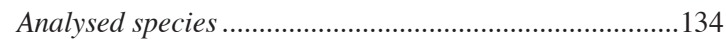

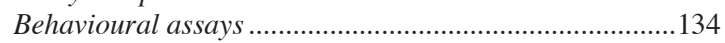

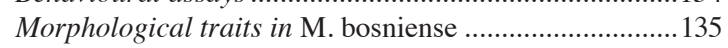

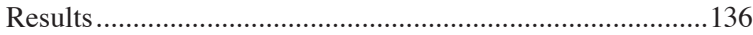

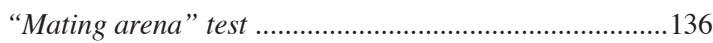

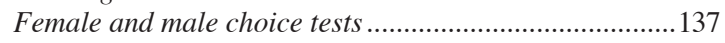

Analyses of morphological traits in M. bosniense ...........137

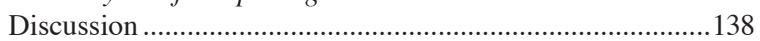

Morphological variation of antennae and legs

between sexes with different mating status ....................... 143

Morphological variation of the head between sexes

with different mating status

Morphological variation of gonopods (promeres

and opisthomeres) between males with different

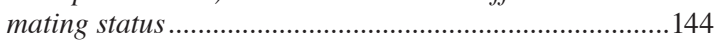

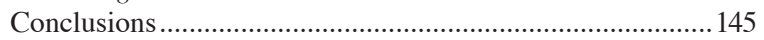

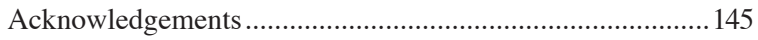

References ..................................................................... 145

\section{Introduction}

Sexual selection, i.e., the mode of selection that emerges due to inequality in mating success (Arnold, 1994), can be seen as a major driving force that favours evolution of traits among members of the same species (Andersson, 1994; Levitan, 2004). Indeed, the role of sexual selection in shaping external morphological variation among conspecific males (e.g. Danielsson, 2001; Jimenez-Perez and Wang, 2004; Willemart et al., 2009) and females (e.g. Stuart-Smith et al., 2007; Bussiere et al., 2008; Xu and Wang, 2010a) has been demonstrated in many studies. Also, a growing body of empirical data shows that, besides the two Darwinian mechanisms of sexual selection (mate choice and competition for mates) (Darwin, 1871), lock-and-key relations (Arnqvist, 1998) and sexual conflict (Eberhard, 1996; Arnqvist and Danielsson, 1999; Kahn et al., 2010; Richmond, 2014) act as agents in shaping of genital traits. Size and shape of the genitalia can have significant influence on mating success, sperm transfer, sperm storage, and paternity in insects (reviewed in Simmons, 2014).

Both on the intraspecific and the interspecific levels, mate choice is one of the key components of the sexual selection theory (Andersson, 1994; McPeek et al., 
2008, 2009; Edward and Chapman, 2011; Dougherty and Shuker, 2014). Differences in mate choice presume the existence of variation of certain trait(s) in males and/or females and occurs when the effects of trait(s) expressed in one sex lead to non-random allocation of reproductive investment (e.g. mating or fertilization) with individuals of the opposite sex (Edward and Chapman, 2011; Edward, 2015). Among trait(s) that can be sexual selection subject(s) and which underlie preferences that lead to mate choice, morphological traits are probably the easiest to quantify. Apart from consideration of linear measurements, a geometric morphometric approach can be applied, and data obtained on size and shape of the trait(s) in focus can be separated and precisely analysed (Zelditch et al., 2004; McPeek et al., 2008, 2009; Gasparini et al., 2011; Cooke and Terhune, 2015). In connection with this, a number of studies are available that link the shape of certain structures (both the "usual morphological" traits and secondary sexual characteristics) with success in mating in the most studied Drosophila species (Menezes et al., 2013; Trajković et al., 2013; LeVasseur-Viens and Moehring, 2014; Richmond, 2014), as well as in other taxa (e.g. Kelly, 2014).

Studies of the potential relationship between sexual behaviour and morphological variability in millipedes (Diplopoda) are mostly focused on representatives of the superorder Juliformia (e.g. Haacker and Fuchs, 1970; Mathews and Bultman, 1993; Barnett et al., 1995; Tadler, 1996; Cooper and Telford, 2000; Jovanović et al., 2017). Precopulatory behaviour typically involves the male's ascending on the female dorsal side, moving toward the anterior part of her body, and positioning his ventral side on the ventral side of the female. During all these stages, the male actively taps the female with his antennae. Gonopods (male secondary sexual structures which represent modified legs of the seventh and/or eighth body ring) serve as sperm carriers (Enghoff, 1985, 1992a; Barnett et al., 1993, 1995; Barnett and Telford, 1996). Since millipedes are characterized by multiple mating, gonopod size and shape could be under the influence of postcopulatory sexual selection.

We assumed that morphological features which are in frequent contact between males and females before copulation occurs may be involved in some sort of mutual assessment and be subject to precopulatory sexual selection. The julid species Megaphyllum bosniense (Verhoeff, 1897) was used to test the impact of morphological variation (both variation of linear measurements, body mass and variation in the shape of certain structures) on mate choice. Mating success of both sexes was tested not only in relation to morphology, but also in relation to previous mating experience. Knowledge of these relationships, together with the results of quantifying behavioural sequences, would contribute to a better understanding of intersexual selection and the mating behaviour of millipedes.

\section{Material and methods}

\section{Analysed species}

Studied species $M$. bosniense is one of the most common millipedes in Serbia (Makarov et al., 2004) and is also distributed in other countries [Albania, Austria, Bosnia and Herzegovina, Bulgaria, Croatia, Greece, Italy, Hungary, Montenegro, Former Yugoslav Republic of Macedonia (FYROM), Romania, Slovenia] (Lazányi et al., 2012). This species is characterized by sexual dimorphism (SD) in body length: females are approximately twice the size of males. For this study, we collected 114 animals (57 individuals of each sex) from Mt. Avala (near Belgrade, Serbia) (Čarapićev Brest, village of Beli Potok; N 4441'32"; E 20³1'06”) during October of 2016. We confirm that no specific permissions were required for collecting millipedes on this site. Also, we confirm that no endgangered and/ or protected species was used in our study. Sex of the collected adults was immediately determined and males and females were placed in separate boxes filled with ground cover from the collecting site. Millipedes were kept for seven days in the laboratory (room temperature, relative humidity of $\sim 60 \%$, natural light regime) to acclimate them before the experiments.

\section{Behavioural assays}

Behavioural traits in $M$. bosniense were scored in three types of tests (mating arena test, female choice test, and male choice test). In the mating arena test, males and females were placed in plastic boxes $(38 \mathrm{~cm} \times 25$ $\mathrm{cm}$ ) filled with leaf-litter, pieces of bark, and soil from the sampling site. We put males and females together into plastic boxes for $\sim 30$ minutes. Each mating pair was scored for behavioural sequences (explained below, Table 1) and transferred to a separate plastic box. Mated and non-mated individuals were further kept individually in plastic boxes filled with leaf litter for 48 hours. Female and male choice tests were conducted after the mating arena test. In the "choice" 
Table 1. Description and quantification of sexual behavior.

\begin{tabular}{|c|c|c|}
\hline Sequences & Abbreviation & Description of sequences \\
\hline Mating latency & ML & $\begin{array}{l}\text { Time elapsed from placing millipedes in the mating experiments until } \\
\text { the beginning of copulation. }\end{array}$ \\
\hline Duration of copulation & $\mathrm{DC}$ & Time scored from the beginning to the end of mating. \\
\hline Contact to copulation time & $\mathrm{CC}$ & $\begin{array}{l}\text { Time scored from contact between female and male that finished with } \\
\text { copulation. }\end{array}$ \\
\hline $\begin{array}{l}\text { Contact duration without } \\
\text { copulation }\end{array}$ & CWC & $\begin{array}{l}\text { Duration of contact between female and male which does not result in } \\
\text { copulation. }\end{array}$ \\
\hline $\begin{array}{l}\text { Time from entrance to contact } \\
\text { with copulation }\end{array}$ & ECC & $\begin{array}{l}\text { Time elapsed from entry of individuals into plastic boxes until contact } \\
\text { with copulation. }\end{array}$ \\
\hline $\begin{array}{l}\text { Time from entrance to contact } \\
\text { without copulation }\end{array}$ & ECWC & $\begin{array}{l}\text { Time elapsed from entry of individuals into plastic boxes until contact } \\
\text { without copulation. }\end{array}$ \\
\hline
\end{tabular}

tests, an individual of one sex and two individuals of the opposite sex (the previous partner from the mating arena test and a new one) were placed in a plastic box $(20 \mathrm{~cm} \times 13 \mathrm{~cm} \times 13 \mathrm{~cm})$ filled with leaf-litter, pieces of bark, and soil from the sampling site. We marked the previous and new partners using UV dust, which is commonly employed to tag insects (Hagler and Jackson, 2001) without modifying their mating behaviour (Terzić et al., 1994). A small amount of redcoloured dust was applied to the telson of the previous partner, while green-coloured dust was applied to the telson of the new partner. A fluorescent UV lamp was used in subsequent determination of the mating partner.

Sexual behaviour was quantified by determining several sequences (Jovanović et al., 2017) (Table 1). Behavioural sequences were scored in the mating arena, female choice, and male choice tests. Additionally, mating success of previously mated and non-mated individuals in the mating arena test was scored in both types of subsequent "choice" tests. The time elapsed between the mating arena and female/ male choice tests was 48 hours (Jovanović et al., 2017). During this time, the individuals were kept individually in plastic boxes filled with leaf litter, regularly fed, and moistened, to relax them from the previous mating.

Descriptive statistical procedures were performed to describe the aforementioned sequences of sexual behaviour. Differences in values of DC, ECC, and CC in the mating arena test and in some of the "choice" tests were determined using the T-test. All statistical analyses were performed in the $\mathrm{R}$ program package (R Development Core Team, 2013; available at http:// www.r-project.org/) and Statistica 7 (StatSoft Inc., Tulsa, OK, USA). To determine differences in success of mating with the previous partner and mating with a new one, the sexual selection coefficient (W) was calculated for males and females separately using JMATING software (the highest mating success, W = 1) (Carvajal-Rodriguez and Rolan-Alvarez, 2006, available at http://acraaj.webs.uvigo.es/JMsoft.htm). The sexual selection coefficient (W) is widely used parameter for estimation of sexual selection effects and it represents the maximum likelihood fitness estimator of one class relative to another (Rolán-Alvarez and Caballero, 2000).

\section{Morphological traits in M. bosniense}

To explore the relationship between mating success and morphological variation of certain traits, traditional and geometric morphometric analyses were carried out.

In performing these analyses, we used the ImageJ program (Abràmoff et al., 2004) to measure several morphological traits (Table 2; see Ilić et al. (2016) for descriptions of linear measurements). Body mass was weighted using a Scout Pro $123^{\circledR}$ scale (Ohaus Corporation, Pine Brook, NJ, USA).

Table 2. List of analyzed morphological traits.

\begin{tabular}{lc}
\hline Morphological trait & Abbreviation \\
\hline Body mass & $\mathrm{BM}$ \\
Body length & $\mathrm{BL}$ \\
Antennal length & $\mathrm{AL}$ \\
$\begin{array}{l}\text { Walking leg length (anterior pair of legs) } \\
\text { taken from the 25th body ring }\end{array}$ & $\mathrm{LL}$ \\
$\begin{array}{l}\text { Trunk width taken from the 24th body ring } \\
\text { Trunk height taken from the 24th body ring }\end{array}$ & $\mathrm{TW}$ \\
\hline
\end{tabular}



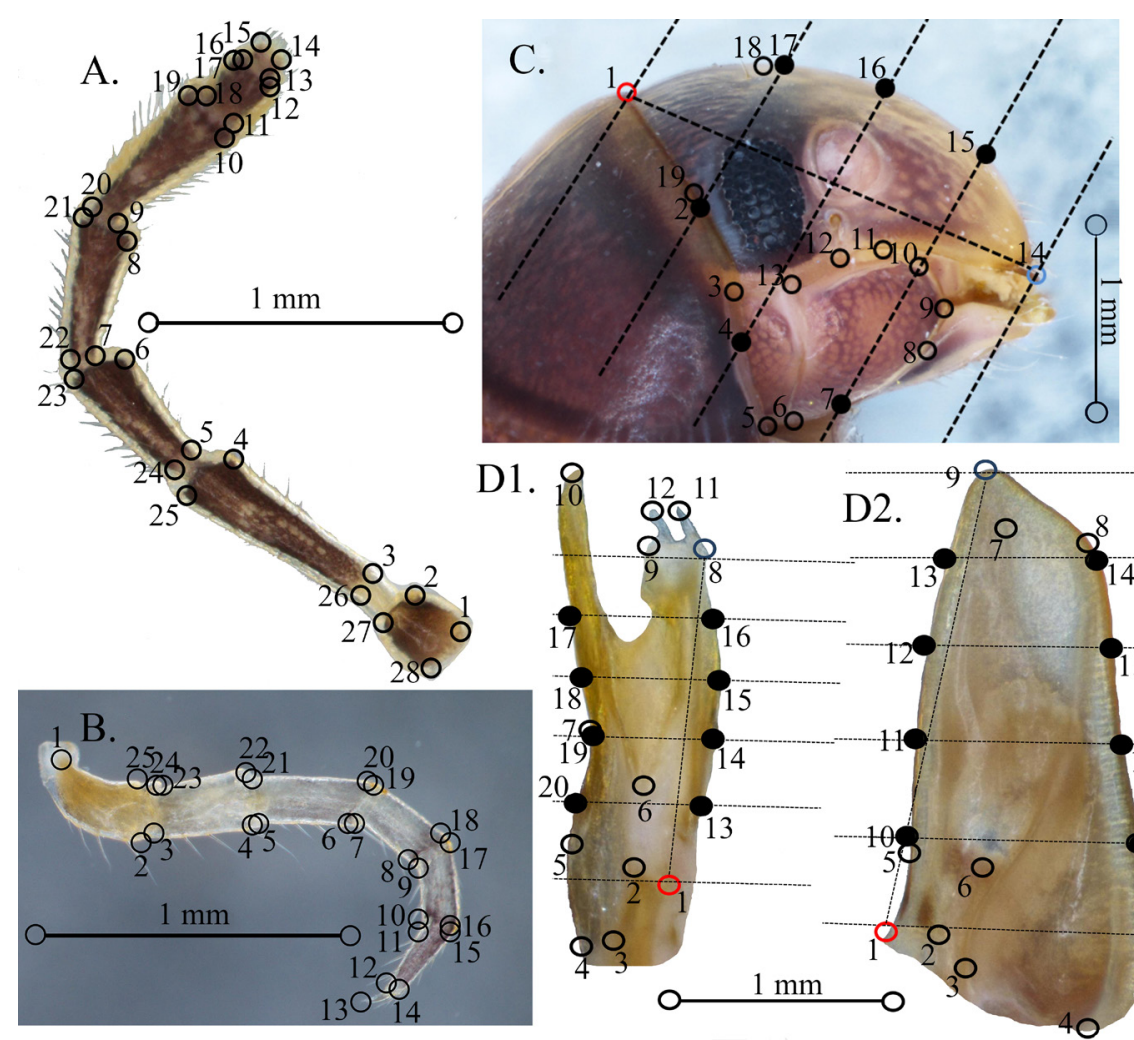

Figure 1. Position of landmarks on antenna (A) and leg (B) of M. bosniense; and position of landmarks and semilandmarks on head (C), opisthomere (D1), and promere (D2). See supplementary data for descriptions of landmarks and semilandmarks.

T-test was used to test the differences in mean values of BM, BL, AL, LL, TW, and TH between sexes with different mating status. Eighty-four mated (42 individuals per sex) and 30 non-mated millipedes (15 individuals per sex) were used for that purpose.

To analyse shape and size of antennae, walking legs, head, and gonopods (promeres, opisthomeres), geometric morphometrics was applied as a method widely used in animal studies (Kaliontzopoulou et al., 2007; McPeek et al., 2008, 2009; Wojcieszek and Simmons, 2011; Brusatte et al., 2012; Richmond, 2014; Changbunjong et al., 2016; Sasakawa, 2016). For these analyses, we used: 1) the antennae in 56 males (41 mated and 15 non-mated, further presented as mated/non-mated) and 57 females $(42 / 15) ; 2)$ the walking legs from the $25^{\text {th }}$ body ring in 57 males $(42 / 15)$ and 56 females $(41 / 15) ; 3)$ the head in 57 males $(42 / 15)$ and 54 females (40/14); and 4) the promeres of 57 males (42/15) and 5) opisthomeres of 56 males $(42 / 14)$. All of the indicated structures were used to estimate morphological variation between individuals with different mating status.
The aforementioned structures (head, antennae, walking legs, gonopods - promeres, and opisthomeres) with a reference scale were photographed using a Nikon DS-Fi2 camera with a Nikon DS-L3 camera controller attached to a Nikon SMZ 1270 binocular stereomicroscope. To determine the position of semilandmarks, it was necessary to make fans at the head, promeres, and opisthomeres in the MakeFan program (available at http://www3 .canisius. edu/ sheets/IMP\%208.htm). TpsDig software (Rohlf, 2008, available at http://life.bio.sunysb.edu/morph/ soft-dataacq.html) was used to position landmarks and semilandmarks. Different numbers of landmarks and semilandmarks were placed, depending on the type of morphological structure (Fig. 1).

Centroid size (CS) for the analysed morphological traits was calculated using the CoordGen6 program (Sheets, 2003, available at http://www3.canisius. edu/ sheets/IMP\%208.htm). Variation in shape of the same traits was examined by Canonical Variate Analysis (CVA) in the MorphoJ program (Klingenberg, 2011, available at http://www.flywings.org.uk/morphoj_ 
Table 3. Descriptive statistics of behavioural sequences: mating latency - ML; duration of copulation- DC; contact to copulation time - CC; contact duration without copulation - CWC; time from entrance to contact with copulation - ECC; and time from entrance to contact without copulation - ECWC. The time is expressed in seconds. For explanation of behavioral sequences see Table 1.

\begin{tabular}{lrrrrrrrr}
\hline & N & Min. & Max. & Median & Variance & Std. Dev. & Quartiles 25\% & Quartiles 75\% \\
\hline ML & 42 & 205.00 & 8025.00 & 1318.50 & 3168232 & 1779.95 & 625.00 & 2510.00 \\
DC & 42 & 103.00 & 23935.00 & 17013.50 & 35581643 & 5965.04 & 14822.00 & 19463.00 \\
CC & 42 & 10.00 & 1127.00 & 162.00 & 52994 & 230.20 & 97.00 & 277.00 \\
CWC & 93 & 4.00 & 367.00 & 35.00 & 6299 & 79.36 & 19.00 & 78.00 \\
ECC & 42 & 104.00 & 7866.00 & 1075.50 & 3315427 & 1820.83 & 371.00 & 2252.00 \\
ECWC & 93 & 71.00 & 7325.00 & 1012.00 & 2165755 & 1471.65 & 571.00 & 2077.00 \\
\hline
\end{tabular}

page.htm). Differences in linear measurements and CS of the aforementioned traits were tested using ANOVA in the $\mathrm{R}$ program package ( $\mathrm{R}$ Development Core Team, 2013; available at http://www.r-project.org/).

\section{Results}

\section{"Mating arena" test}

In observation of the sexual behaviour of individuals in the mating arena test, it was noticed that males of M. bosniense (Fig. $2 \mathrm{~A}$ ) were the more active when searching for mates, and attempted to establish numerous contacts with females. If the female is receptive, it will allow access to its gonopores (Fig. 2 B), which designate this sex as the "choosier" one in mate selection. Precopulatory behaviour in this species (Fig. $2 \mathrm{C}-\mathrm{F}$ ) was quite similar to that recorded in the earlier studied species Pachyiulus hungaricus (Karsch, 1881) (see Jovanović et al., 2017). Behavioural sequences (ML, DC, CC, ECC, ECWC, and CWC) explored by descriptive statistics are presented in Table 3 . Out of all contacts, $51 \%$ resulted in copulation (Fig. 2 G-I).

\section{Female and male choice tests}

Out of all achieved copulation in the female choice test (64\% out of 31 copulations), females mostly chose the previous partner for subsequent copulation (in $80 \%$ of cases). A similar pattern was detected in the male choice test: $47 \%$ of all contacts resulted in copulation (out of 21 copulation). Males also mostly chose the previous mating partner for copulation (in $85 \%$ of cases). When considering "contacts" (the male's ascending on the female dorsal side and moving toward the anterior part of her body), $77 \%$ of all contacts (with and without copulations) were observed with the previous males in the female choice test. In the male choice test, on the other hand, $68 \%$ of all contacts were observed with previous females. In most cases, one contact was sufficient for accomplishing copulation in both the female and the male choice tests (75 and 69\%,
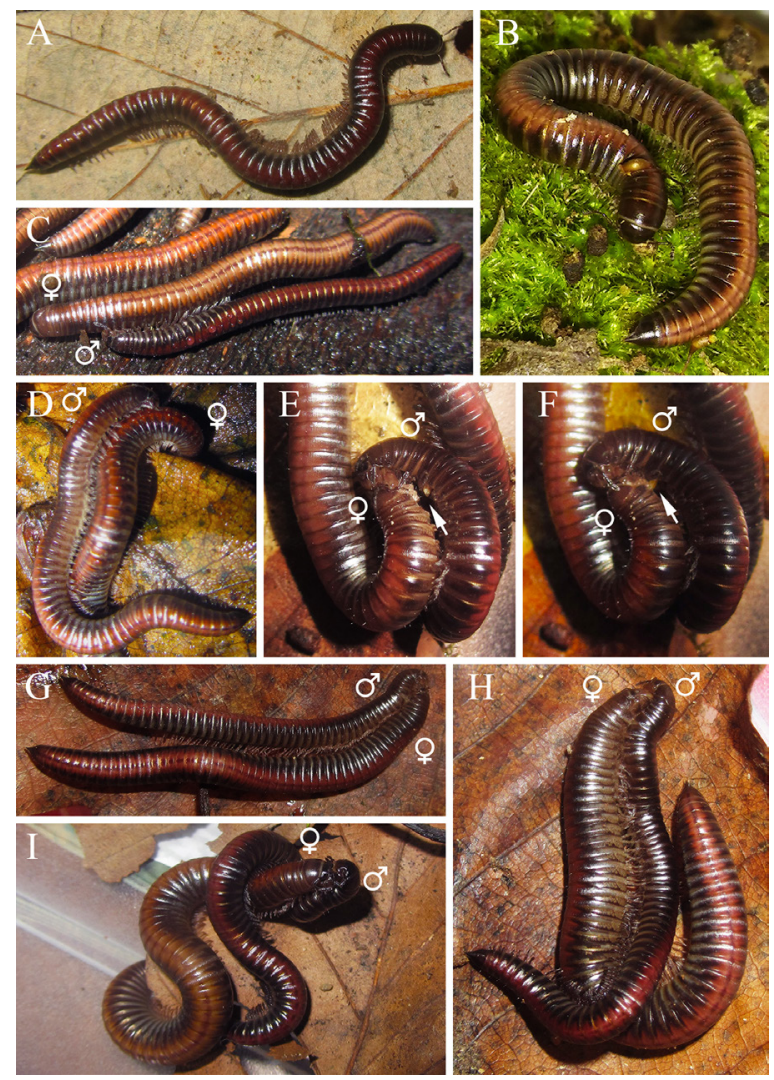

Figure 2. Sequences of sexual behaviour in M. bosniense. A male; B - female; C, D - contact; E, F - extrusion of gonopods (arrows); G, I, H - copulation (photo: B. Ilić). 
Table 4. Differences of ML, DC, CC, and ECC between two successive behavioral tests (mating arena and male/female choice tests). Significant differences are highlighted in bold. The time is expressed in seconds. For abbreviations see Table 1.

\begin{tabular}{|c|c|c|c|c|c|c|c|c|}
\hline & Male & Female & Max. & Median & Variance & Std. Dev. & Quartiles 25\% & Quartiles $75 \%$ \\
\hline & $\mathrm{N}$ & $I-$ mating arena & II "choice" test & $P$-value & $N$ & $I-$ mating arena & II "choice" test & $P$-value \\
\hline ML & 21 & $2122.29 \pm 427.07$ & $1991.81 \pm 259.61$ & $\mathrm{P}=0.7954$ & 31 & $2010.39 \pm 323.20$ & $942.36 \pm 131.81$ & $P=0.0033$ \\
\hline DC & 21 & $18081.00 \pm 739.99$ & $16033.29 \pm 790.40$ & $\mathrm{P}=0.0658$ & 31 & $17520.13 \pm 609.18$ & $19455.16 \pm 558.08$ & $P=0.0225$ \\
\hline $\mathrm{CC}$ & 21 & $230.62 \pm 34.64$ & $279.10 \pm 52.39$ & $\mathrm{P}=0.4447$ & 31 & $241.81 \pm 42.83$ & $164.94 \pm 22.81$ & $\mathrm{P}=0.1184$ \\
\hline ECC & 21 & $1891.71 \pm 430.63$ & $1712.71 \pm 275.43$ & $\mathrm{P}=0.7280$ & 31 & $1768.61 \pm 328.76$ & $777.42 \pm 132.06$ & $P=0.0069$ \\
\hline
\end{tabular}

Table 5. Analyses of morphological traits (body mass and linear measurements), as source of variation, between males and females with different mating status. Significant differences are highlighted in bold.

\begin{tabular}{lcccc}
\hline & \multicolumn{2}{c}{ Mated/non-mated males } & \multicolumn{2}{c}{ Mated/non-mated females } \\
\hline Traits & T-values & P-values & T-values & P-values \\
\hline Body mass (BM) & -0.3263 & 0.7454 & 2.8375 & $\mathbf{0 . 0 0 6 3}$ \\
Body length (BL) & -0.1033 & 0.9181 & 2.1283 & $\mathbf{0 . 0 3 7 8}$ \\
Antennal length (AL) & -0.1589 & 0.8744 & 1.8458 & 0.0703 \\
Leg length (LL) & 1.1517 & 0.2544 & 1.0982 & 0.2770 \\
Trunk width (TW) & -0.2885 & 0.7740 & 0.6194 & 0.5382 \\
Trunk height (TH) & -1.0988 & 0.2766 & 0.4681 & 0.6415 \\
\hline
\end{tabular}

respectively). A smaller percentage of copulations was recorded after two and three contacts in both types of "choice" tests (24 and 30\%, respectively).

The number of copulations was significantly higher with the previous partner than with a new partner in both types of "choice" tests [female choice test: W1 (new mating partner) $=0.24, \mathrm{SD}=0.1149, \mathrm{P}<0.0001$, $\mathrm{W} 2$ (previous mating partner) $=1$; male choice test: $\mathrm{W} 1$ (new mating partner) $=0.17, \mathrm{SD}=0.1129, \mathrm{P}<$ 0.0001 , W2 (previous mating partner) $=1]$.

Furthermore, no significant differences of DC, ECC, CC, and ML were recorded in males that mated twice in the mating arena and male choice tests. On the other hand, significant differences of DC, ECC, and ML were obtained in females that mated twice in the mating arena and female choice tests (Table 4).

Analyses of morphological traits in M. bosniense

We detected the existence of variability in the morphology of certain structures between males and females with different mating status. Mated females were larger with higher values of body mass and head CS than non-mated females (Figs. 3 and 4, Tables 5 and 6). Except in the case of body mass and body length in females, no differences of linear measurements were observed between mated and non-mated individuals (Table 5). CVA showed clustering of the groups by CV2 axis, illustrating that the proximal part of the head was sharper in non-mated individuals of both sexes (Fig. 5). Promere shape differed significantly between males with different mating status (Table 6). Namely, the bases of promeres were wider in non-mated males (Fig. 8). In the case of other parts of the body (antennae, walking legs, opisthomeres), significant differences in size and shape were not observed (Table 6; Figs. 6, 7, and 9).

\section{Discussion}

In laboratory conditions, $M$. bosniense established numerous body contacts, more than half of which resulted in copulation. Sexual selection coefficient (W) calculated in this study indicated that preferences toward the previous partner were expressed in both "choice" tests. We presumed that females use a combination of different types of stimuli in recognition of suitable mating partner: morphological traits under the action of sexual selection, chemical/olfactory cues (such as volatile pheromones, cuticular components, 
mandibular secretion, secretion from the coxal glands) or auditory stimuli (Haacker, 1969; Carey and Bull, 1986; Tadler, 1996, Wesener et al., 2011). In the context of sexual selection, exchange of visual information is common in diurnal animals living in open habitats. In millipedes, because of their way of life in natural conditions, the visual stimuli themselves could not play an important role in determining mating partner. However, the quality of morphological traits could be detected indirectly, through other sensory domains (e.g. through the quality and/or intensity of tactile/mechanical stimulation provided by certain morphological structures).

A tendency toward mating with previously chosen partners was reported in millipedes in laboratory conditions (Telford and Dangerfield, 1993a; Jovanović et al.,2017). Mating with the same partner could be the result of assessment of his/her good health condition or his/her high genetic quality. Moreover, mating with the same partner could be explained as a form of mate guarding. The opposite strategy was observed, for example, in some insect and pseudoscorpion species [Tregenza and Hosken (2005) and references therein]. Selection of a different mating partner may ensure successful fertilization if the first male was sterile or of poor quality. Mating with a different partner could provide genetic diversity of the progeny as well.

Significant differences were observed in some morphological traits that could be involved in sexual selection (body mass, head size, and head shape) between mated and non-mated females, as well as in head and gonopod promere shape between mated and non-mated males. These results are consistent with data obtained in many arthropods indicating that
A.

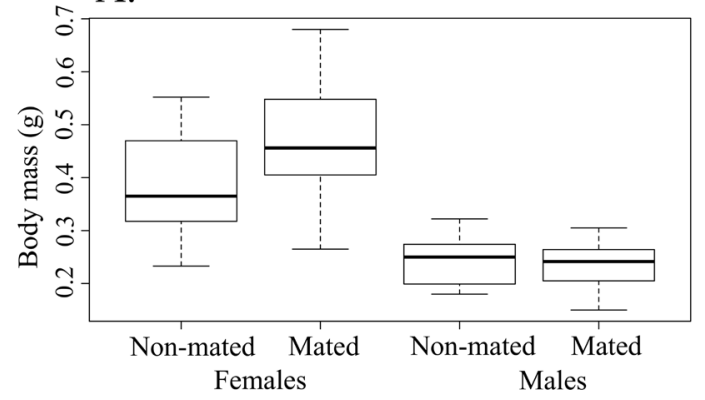

C.

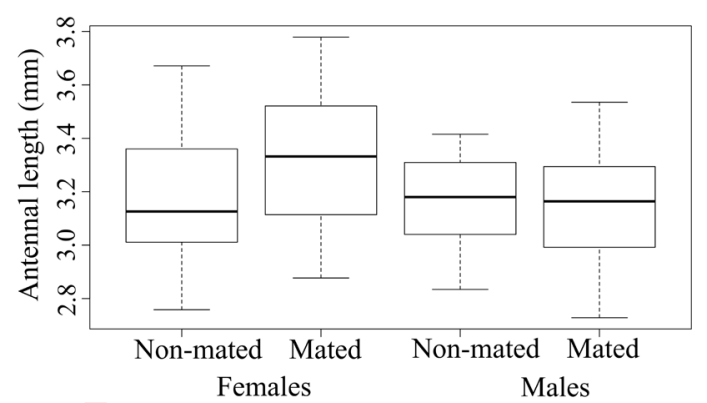

E.

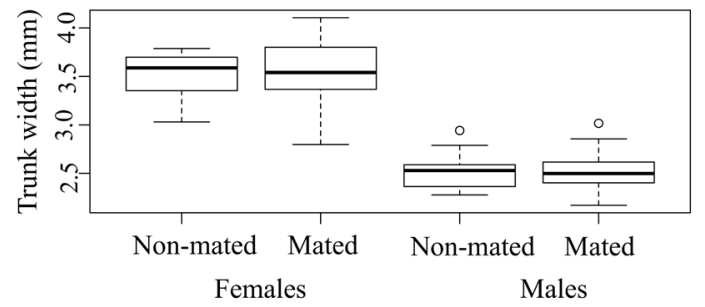

B.

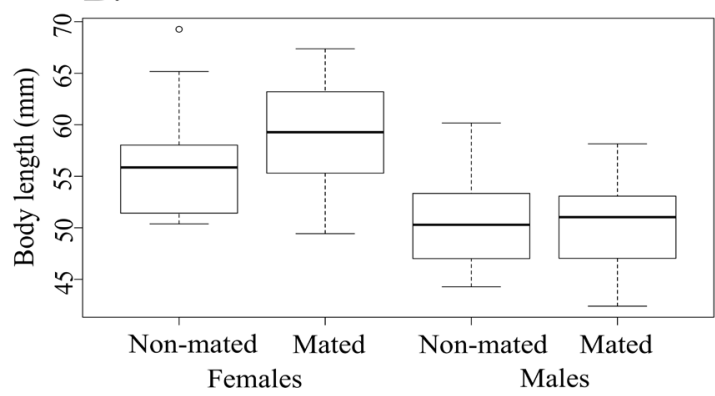

D.

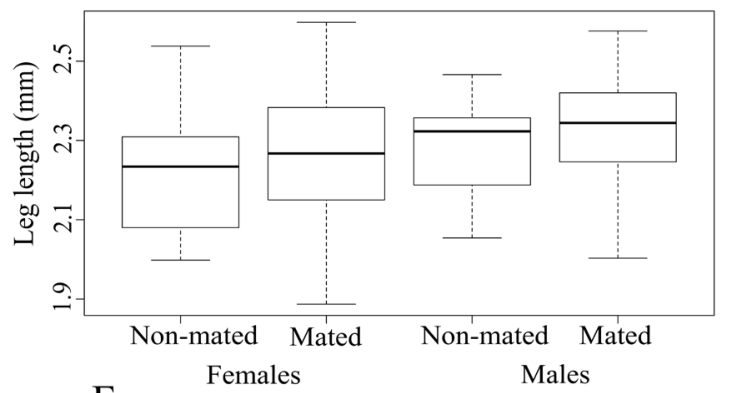

F.

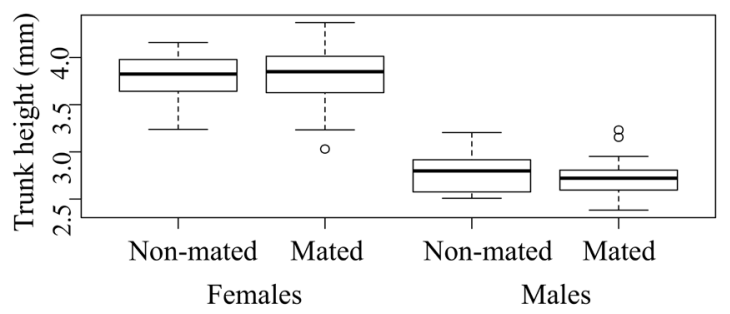

Figure 3. Morphological variation of body mass (A), body length (B), antennal length (C), leg length (D), trunk width (E), and trunk height $(\mathrm{F})$ between males and females with different mating status. The median with the first and the third quartiles is shown (in boxes), together with the range of variation and outliers. 
A.

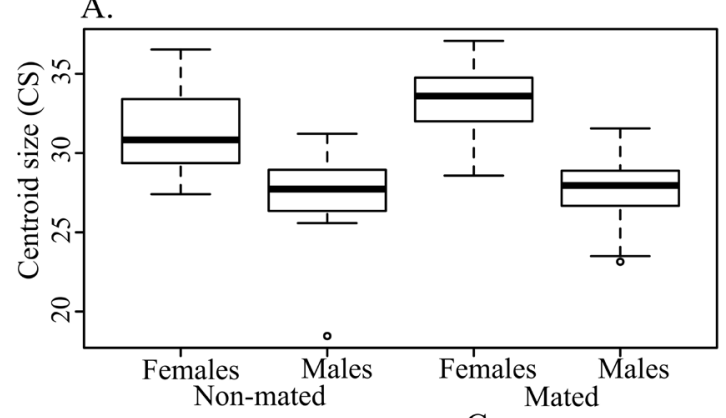

C.
B.

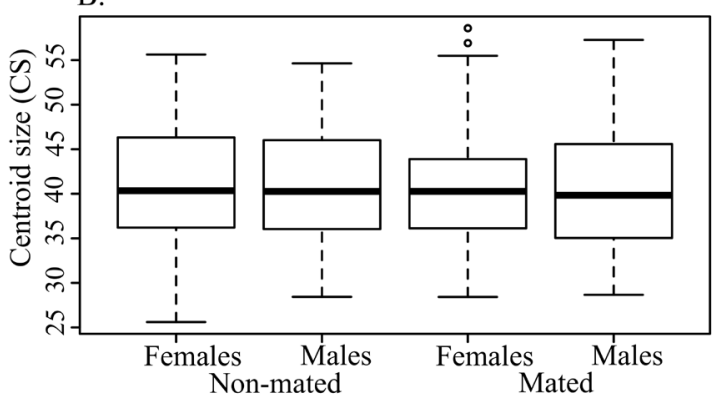

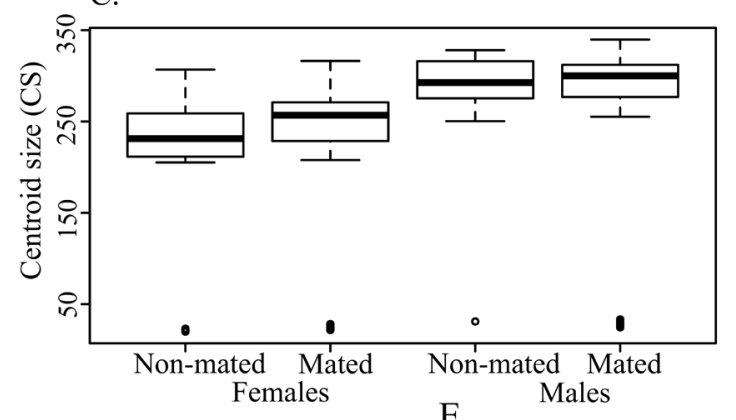

D.

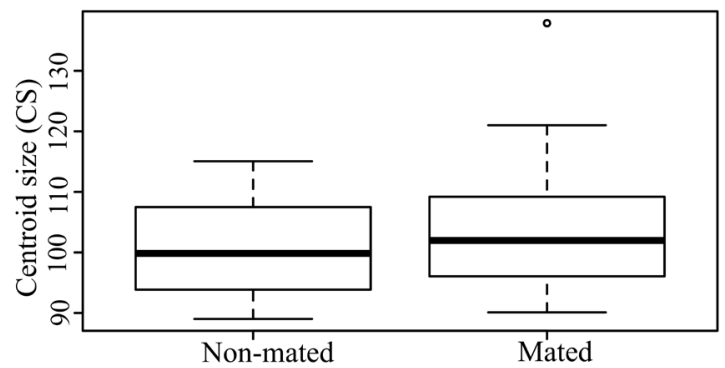

E.

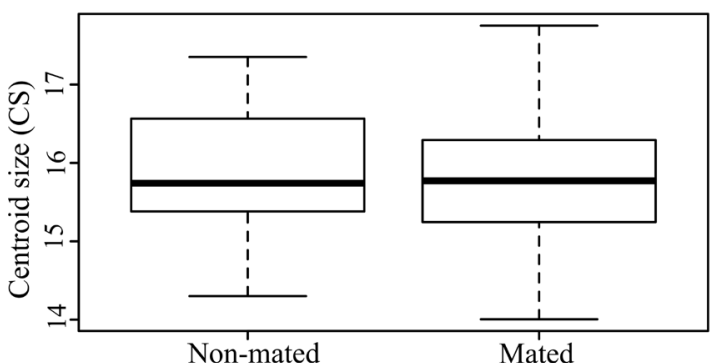

Figure 4. Morphological variation in centroid size (CS) of head (A), antennae (B), walking legs (C), promeres (D), and opisthomeres (E) between individuals with different mating status. The median with the first and the third quartiles is shown (in boxes), together with the range of variation and outliers.

Table 6. Analysis of centroid size (CS) and shape of certain morphological traits, as source of variation, between males and females with different mating status. Significant differences are highlighted in bold.

\begin{tabular}{lcccc}
\hline Morphological traits & \multicolumn{2}{c}{ Mated/non-mated males } & \multicolumn{2}{c}{ Mated/non-mated females } \\
\hline Head & CS & Shape & CS & Shape \\
Antennae & 0.9984 & $\mathbf{0 . 0 0 2 6}$ & $\mathbf{0 . 0 0 1 2}$ & 0.0004 \\
Walking legs & 0.9824 & 0.8728 & 0.9999 & 0.2073 \\
Promeres & 0.9163 & 0.6397 & 0.5176 & $/$ \\
Opisthomeres & 0.3435 & $\mathbf{0 . 0 0 6 4}$ & $/$ & $/$ \\
\hline
\end{tabular}




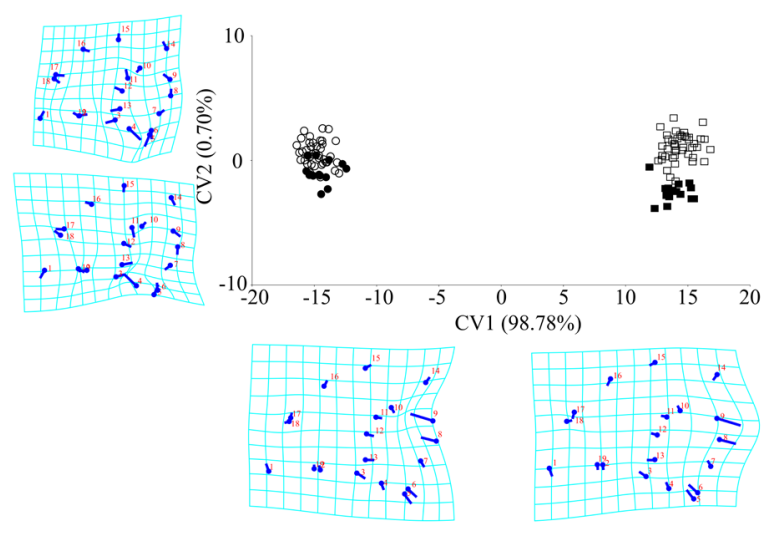

Figure 5. Canonical Variate Analysis (CVA) of differences in head shape between males and females with different mating status (rectangles: black - non-mated males, white - mated males; circle: black - non-mated females, white - mated females).

morphological variability of sexual and non-sexual traits influenced their mating success (Polihronakis, 2006; Zhou et al., 2012; Menezes et al., 2013; Kamimura, 2014; Outomuro et al., 2016; Bertram et al., 2017).

Behavioural traits were scored and quantified in mating arena and "choice" tests. We obtained differences in some behavioural characteristics (ML, DC, and ECC), as well as in certain morphological traits (linear measures, centroid size, and shape values) between individuals with different mating status. It seems that mate choice in this species is quite complex, since evaluation of mating partners was based on a number of traits tested in this study (previous mating experience, several important behavioural steps, and size and shape of certain sexual and non-sexual structures).

The sequences of precopulatory behaviour in this species are quite similar to those previously described in other juliform millipedes (Haacker and Fuchs, 1970; Tadler, 1996; Jovanović et al., 2017 and references therein). The male uses his anterior pairs of legs to get a grip on the female's head, after which the extrusion of gonopods follows. An intermediate step between the grip and actual copulation is the charge of gonopods with spermatophores (Barnett and Telford, 1996; Minelli and Michalik, 2015). The copulating pair can assume different positions, from parallel to those where the male is coiled around the female in varying degrees with the anterior or posterior part of his body. Components of mating behaviour, mating latency (ML), and copulation duration (DC) in some

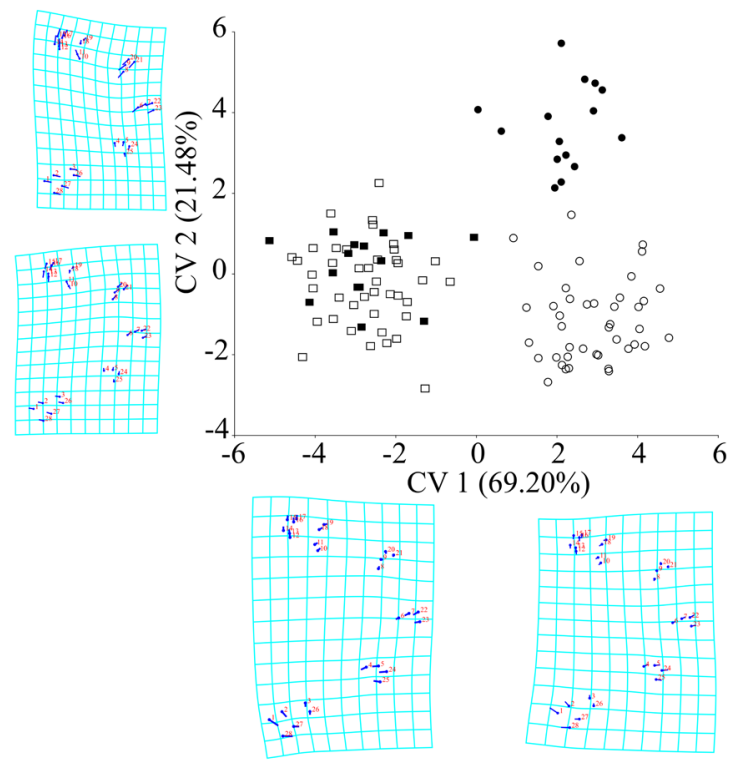

Figure 6. Canonical Variate Analysis (CVA) of differences in antennal shape between males and females with different mating status (rectangles: black - non-mated males, white-mated males; circle: black - non-mated females, white - mated females).

Drosophila species were indicators of mate choice based on previous mating experience [Pavković-Lučić and Kekić (2009) and references therein]. Our results showed that ML and ECC lasted for a significantly shorter time in the female choice test than in the mating arena test. However, the pairs formed in the female choice test copulated significantly longer than in the mating arena. In other studies, it was found that the duration of copulation can be prolonged as a result of a male-biased operational sex ratio (OSR), considering that there were two males and only one female available (Telford and Dangerfield, 1990; Cooper, 2016).

Long copulation duration, a possible adaptation in connection with mate guarding and sperm competition, was previously observed in spiders (Schneider et al., 2006; Herberstein et al., 2011), diplopods (Telford and Dangerfield, 1990, 1993a,b; Barnett and Telford, 1996; Rowe, 2010; Cooper, 2016), chrysomelids (Dickinson, 1997), and many insects (e.g. SillénTullberg, 1981; Schöfl and Taborsky, 2002; Afaq and Omkar, 2017). In M.bosniense, the long copulation ( 5 hours) could be explained, at least partially, in terms of mate guarding. During this long-lasting copulation, the male protects his investment, a behavioural trait that could result from the need for manifestation of 


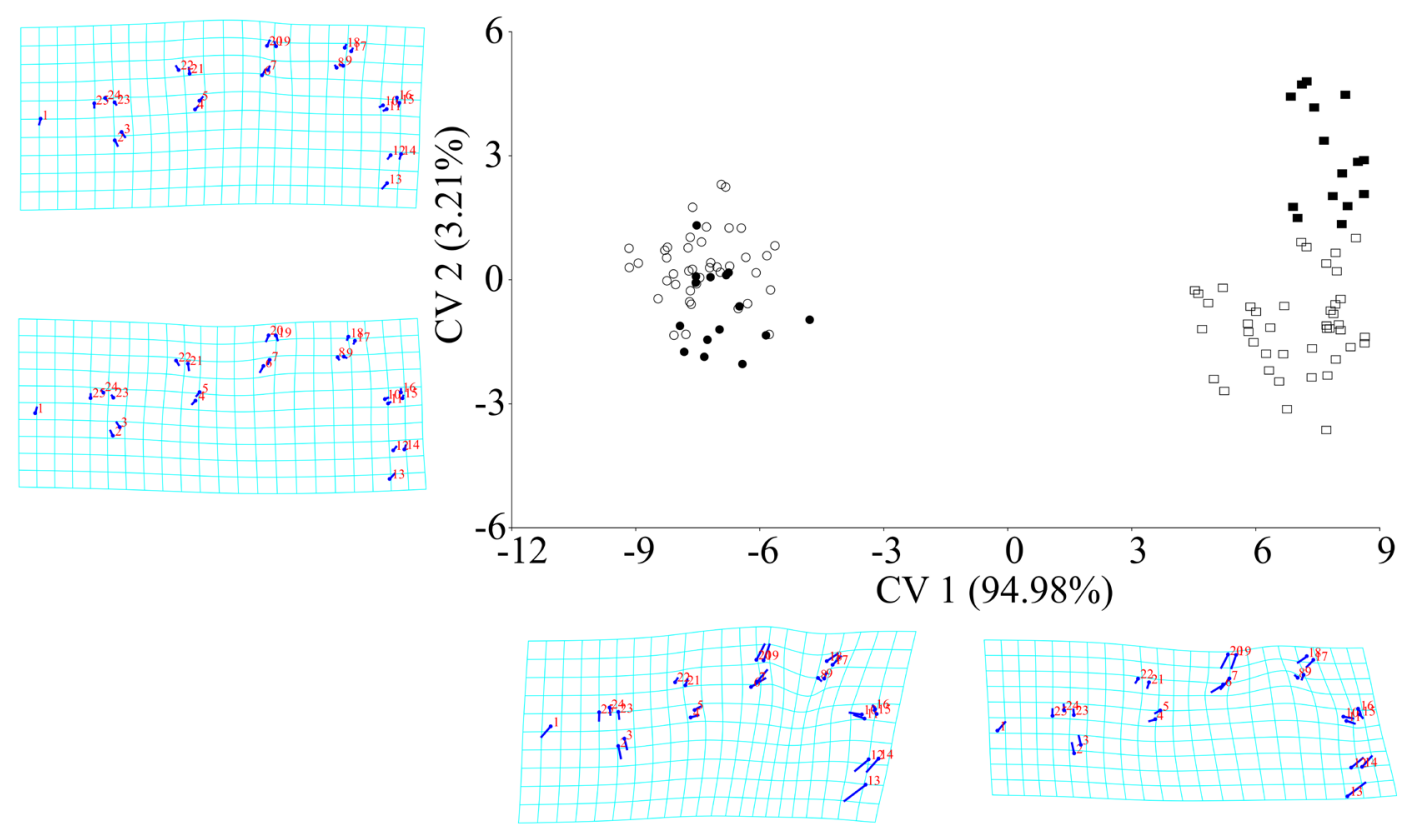

Figure 7. Canonical Variate Analysis (CVA) of differences in leg shape between males and females with different mating status (rectangles: black - non-mated males, white - mated males; circle: black - non-mated females, white - mated females).

sperm precedence (Harari et al., 2003; Cooper, 2016). A positive correlation between the amount of sperm in the female receptacula, and the duration of copulation with the last male was detected in some millipedes (Barnett and Telford, 1994) and insects (Simmons, 2001). It is possible that a male millipede can manipulate his own ejaculate, distributing it closer to the part of the oviduct where fertilization occurs (Barnett and Telford, 1994), i.e., performing sperm repositioning, which is common in insects (Simmons, 2001; Córdoba-Aguilar et al., 2003; Xu and Wang, 2010). In some millipedes, the volume of the second male ejaculate significantly increased within 24 hours after copulation (Cooper, 2015), or the volume of the first male ejaculate significantly decreased during the same period (Barnett et al., 1995). Sperm competition may act as an agent in the shaping of genital structure(s) involved in sperm removal (Kamimura, 2000) and sperm mixing (Barnett et al., 1995; Simmons, 2001). In millipedes, the flagellum can have such a role (Tadler, 1996; Minelli and Michalik, 2015). Wojcieszek and Simmons (2011) revealed a relationship between paternity success and the presence of a spiral, spike-like shape of the tip of the gonopods, which could be responsible for sperm manipulation and/or female stimulation. We assume that the opisthomere processes have a similar function in M. bosniense. In some millipedes, one of the effective mechanisms for preventing subsequent copulation is the use of copulation plugs preventing future copulations with another male (Barnett and Telford, 1994; Cooper, 2016). However, we did not observe the presence of copulation plug in our sample. Before the female utilizes ejaculates, the male must maximize the likelihood of reproduction, which requires time spent not just in guarding the female, but also in maintaining genital contact. In that manner, the male could establish himself as one of the potential "choices", if not the most successful one.

One of the basic prerequisites for "choosiness" is morphological variation of the potential partners (Bonduriansky, 2001). Different morphological traits (i.e., linear and shape measurements, centroid size values) were analysed as the potential basis for mate preference and mating success in a number of previous studies (Zhou et al., 2012; Head et al., 2013; Menezes et al., 2013; Ali et al., 2014; Outomuro et al., 2016; Bertram et al., 2017). In the present study, body mass and body length differed significantly between mated and non-mated females, i.e., mated females had a larger values of both traits. We investigated mating success as one of the components of reproductive success, others being fecundity, paternity success and parental care. However, explanation of our results may 
rest upon literature evidence of positive correlations between fecundity and body mass in millipedes (Heath et al., 1974), Orthoptera (Sturm, 2016) and in oviparous species of several insect orders (Honěk, 1993). Larger females with thicker abdomens (Yang and Wang, 2004), greater body length (Lu et al., 2013), and body width (Cooper, 2017) were more attractive to males in different species. This could result not only from possessing a greater number of eggs, but also from being capable of receiving a larger volume of ejaculate (Lu et al., 2013; Cooper, 2017). In the family Julidae, paired ovaries extend from $15^{\text {th }}$ to the last leg-bearing segment, and eggs can take up more than half the segment's volume (Hopkin and Read, 1992). Further, M. bosniense is an euanamorphic species (individuals moult throughout entire life), body size is linked with age (Enghoff, 1992b). It implies that the age of an individual could also contribute to mating preference/success.

\section{Morphological variation of antennae and legs between} sexes with different mating status

In millipedes, the male's tapping the head of the female with his antennae can be described as male courtship and/or mate assessment (Carey and Bull, 1986). This type of behaviour is also common in insects (Møller and Zamora-Muñoz, 1997; Bonduriansky, 2001). In

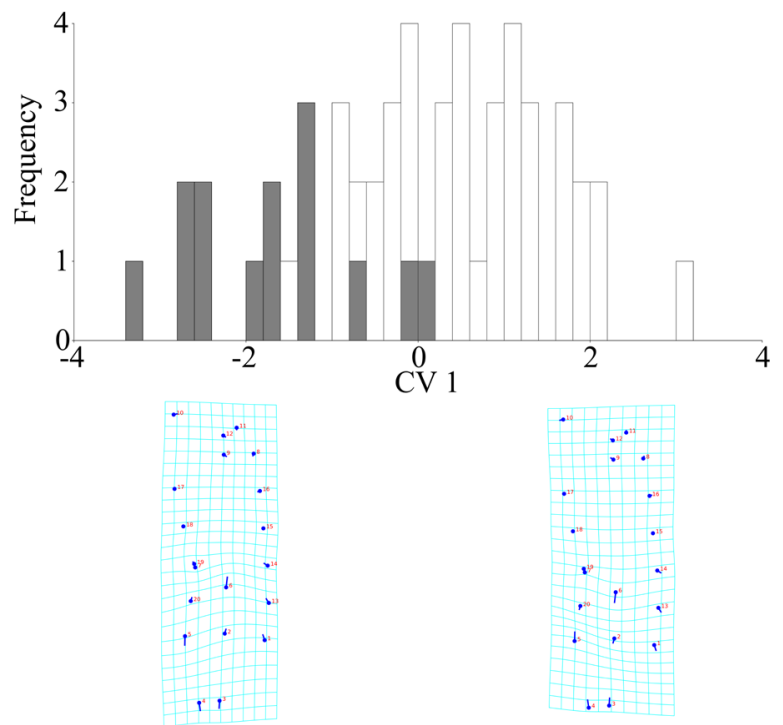

Figure 8. Canonical Variate Analysis (CVA) of differences in promere shape between males with different mating status (bars: white - mated males; grey - non-mated males). the process of courtship and/or mate assessment, the antennae have an important role in millipedes, as shown by Carey and Bull (1986) in an experiment with the julid Ommatoiulus moreleti (Lucas, 1860). Males whose whole antennae or just the antennal tips were removed mated less frequently than did males which were not subjected to this procedure, while females with different degrees of antennal removal mated as frequently as did ones whose antennae remained intact. On the other hand, the length of undamaged and intact antennae was not significantly different between mated and non-mated longhorn beetle Stenurella melanura (Linnaeus, 1758) males (Møller and Zamora-Muñoz, 1997). This was corroborated in our study; namely, no significant effect of antennal size and shape (females: $\mathrm{P}=0.9999$, males: $\mathrm{P}=0.9824$; females: $\mathrm{P}=0.1103$, males: $\mathrm{P}=0.8728$; respectively) on mating decisions was observed.

It is known that possession of longer legs used in grasping (Garga et al., 1997; Sugano et al., 2008) or courtship behaviour (Amin et al., 2012) is positively correlated with male mating success in insects and spiders. Since males "walk" across the whole length of the female's body, we supposed that the length and/or shape of the legs could be important factors providing suitable tactile stimulation in $M$. bosniense. A similar type of behaviour is observed in the hymenopteran Cephalonomia tarsalis (Ashmead, 1893) (Cheng et al., 2004). However, our results gave no support to the

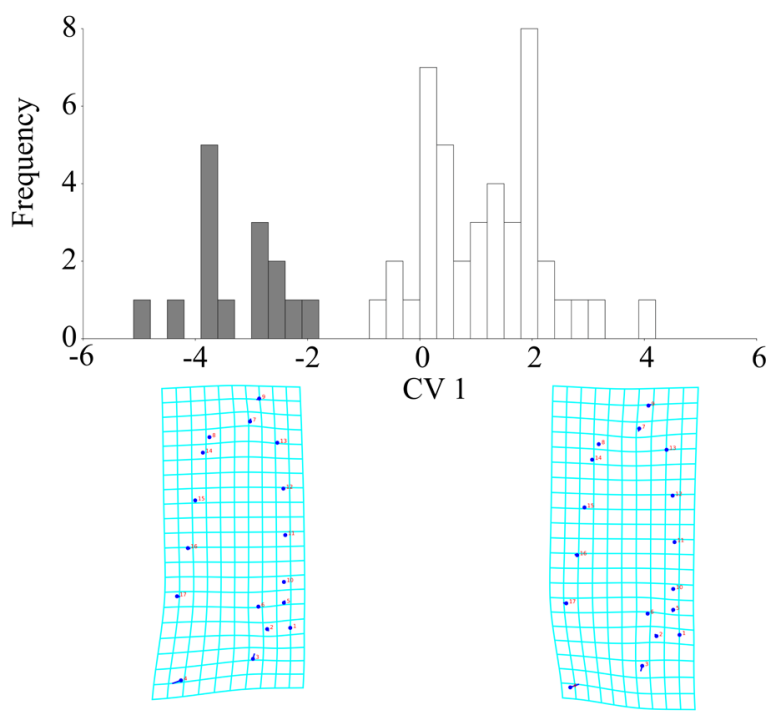

Figure 9. Canonical Variate Analysis (CVA) of differences in opisthomere shape between males with different mating status (bars: white - mated males; grey - non-mated males). 
presumption that this type of stimulation is important for successful mating (CS: females, $\mathrm{P}=0.5176$, males, $\mathrm{P}=0.9163$; shape: females, $\mathrm{P}=0.2073$, males, $\mathrm{P}=$ 0.6397). The significance of walking legs for the male mate search effort was previously noted in the paradoxosomatid Cladethosoma clarum Chamberlin, 1920 (Rowe, 2010). In this species, males possess longer legs than females. Nevertheless, since in $C$. clarum copulation lasts only several minutes, the number of receptive females could be the main driving force influencing male mating success.

Apart from tactile stimuli, courtship behaviour in millipedes can include exchange of stimuli from other sensory domains. Other cues were not investigated here, although it is presumed that volatile pheromones or cuticular components may play an important role in the mating behaviour of some millipedes (Carey and Bull, 1986). Mandibular secretion is observed in the julid Julus terrestris Latzel, 1884 (Haacker, 1969) and in the pachybolid Centrobolus Cook, 1897 after copulation has already started (Cooper and Telford, 2000). In Cylindroulus boleti (C. L. Koch, 1847) and Brachiyulus lusitanus (Verhoeff, 1898), males released a secretion from the coxal glands of the second pair of legs in the mouth of females during the first minute of copulation (Tadler, 1996). Males of the family Sphaerotheriidae or the genus Loboglomeris (both belonging to order Glomerida) use specific sound to induce vibrational patterns that would appear to counter the coiling behaviour of females (Haacker, 1968; Wesener et al., 2011).

\section{Morphological variation of the head between sexes with different mating status}

Precopulatory sexual selection can affect morphological variation of the head in insects (Rodriguero et al., 2002; Bonduriansky and Rowe, 2003). Females of some insects distinguished their potential mates on the basis of head morphology, eye length, face width (Rodriguero et al., 2002) or on the basis of head elongation (Bonduriansky and Rowe, 2003).

As already mentioned, the head of the female in $M$. bosniense is an area where the male spends some time tapping with his antennae, as it is "the attachment region" after formation of a mating pair. In the present study, we found that mated and nonmated individuals of both sexes differed significantly in head shape (females: $\mathrm{P}=0.0004$; males: $\mathrm{P}=$ 0.0026). As the male positions himself above the female grasping her head, shape of the head could be important for achieving the position needed for a successful copulation. The larger heads in mated females provide larger areas for males to perform courtship and/or mate assessment.

Morphological variation of gonopods (promeres and opisthomeres) between males with different mating status

Morphological variation of somatic and genital traits may have significant impact on mating success in many animal groups (Langerhans et al., 2005; Pavković-Lučić et al., 2009; Ponlawat and Harrington, 2009; Cator and Zanti, 2016). Somatic traits are under the influence of precopulatory sexual selection (Jones and Ratterman, 2009), while sexual traits can be subjected to both pre- and postcopulatory selection (Polihronakis, 2006; Kamimura, 2014; Simmons, 2014). When considering genital traits, for example, in water striders, non-intromittent genital traits are under precopulatory, while intromittent genital traits are under postcopulatory sexual selection (Rowe and Arnqvist, 2012).

Millipede gonopods are morphologically complex integrated units with different roles during copulation (Wojcieszek et al., 2012). In several julid species, the function of the promeres are probably only to open the vulvae. On the other hand, the opisthomeres - onto which a sperm droplet is secreted - are necessary for insemination (Tadler, 1996). This author considered that the Julid gonopods evolved toward being opisthospermous (sperm transfer by posterior gonopods). Promeres are regarded as a structures without a direct sperm transfer function. When reaching vulva, promeres are pressed against the operculum, which "covers the gonopore from anterior" (Koch, 2015). Therefore, it is important for members of the family Julidae to possess well developed promeres. Gonopods of $M$. bosniense are characterized by a well-developed promeres, as well as opisthomeres with two smaller processes and a larger posterior one (Lazányi and Vagalinski, 2013). Our results show that only promere shape differs between mated and non-mated males (promere shape: $\mathrm{P}=0.0064$; opisthomere shape: $\mathrm{P}=0.1548$ ), suggesting that shape of "genital" parts has more important role in mating in comparison with the size of the same structures. These findings corroborate results of the study on water striders where the shape of genital structures has greater importance in insect genital evolution (Rowe and Arnqvist, 2012). 


\section{Conclusions}

In $M$. bosniense, it seems that both sexes can exert precopulatory as well as cryptic choice. Here we examined morphometric traits that could determine a suitable mating partner and measured some sequences of mating behaviour that imply cryptic choice on the background of extremely long copulation during which mate guarding and possible ejaculate manipulation occur. Using a combination of different types of stimuli, males of $M$. bosniense recognize females with greater body mass and head shape corresponding to their own to achieve a firm grasp and head-abovehead copulation position. Furthermore, differences in promere shape contribute to male mating success. Previous mating experience also influence mate choice in this species.

\section{Acknowledgements}

This work was supported by the Serbian Ministry of Education, Science, and Technological Development (Grant No. 173038). The authors are highly grateful to Mr. Raymond Dooley for his help in preparing the English version of the manuscript. Special thanks to three reviewers for their valuable comments that improved the manuscript. Also, the authors deeply appreciate the selfless assistance of Professor Emilio Rolán-Alvarez (University of Vigo, Vigo, Spain) and his suggestions regarding the section on statistical analyses.

\section{References}

Abràmoff MD, Magalhães PJ, Ram SJ. 2004. Image processing with ImageJ. Biophotonics International 11: 36-42.

Afaq U, Omkar O. 2017. Prolonged copulation in the parthenium beetle, Zygogramma bicolorata: An alternative male tactic to amplify sperm transfer, reproductive attributes and paternity outcomes. Entomologia Experimentalis et Applicata 164: 45-53. DOI: 10.1111/eea.12595.

Ali AK, Primicerio R, Folstad I. 2014. Female morphology and male mating success in the calanoid copepod, Eudiaptomus graciloides. Journal of Plankton Research 36: 1216-1223.

Amin MR, Bussiere L, Goulson D. 2012. Effects of male age and size on mating success in the bumblebee Bombus terrestris. Journal of Insect Behavior 25: 362-374.

Andersson MA. 1994. Sexual selection. Princeton University Press, Princeton, New Jersey.

Arnold SJ. 1994. Is there a unifying concept of sexual selection that applies to both plants and animals? The American Naturalist 144 (suppl.): S1-S12.

Arnqvist G. 1998. Comparative evidence for the evolution of genitalia by sexual selection. Nature 393: 784-786.

Arnqvist G, Danielsson I. 1999. Copulatory behavior, genital morphology, and male fertilization success in water striders. Evolution 53: 147-156.

Barnett M, Telford SR. 1994. The timing of insemination and its implications for sperm competition in a millipede with a prolonged copulation. Animal Behaviour 48: 482-484.

Barnett M, Telford SR. 1996. Sperm competition and the evolution of female genitalia. Mémoires du Muséum National d'Histoire Naturelle 169: 331-339.

Barnett M, Telford SR, De Villiers CJ. 1993. Sperm displacement in a millipede? An investigation into the genital morphology of the southern African spirostreptid millipede Orthoporus pyrhocephalus. Journal of Zoology 231: 511-522.

Barnett M, Telford SR, Tibbles BJ. 1995. Female meditation of sperm competition in the millipede Alloporus uncinatus (Diplopoda: Spirostreptidae). Behavioral Ecology and Sociobiology 36: 413-419.

Bertram SM, Loranger MJ, Thomson IR, Harrison SJ, Ferguson GL, Reifer ML, Corlett DH, Gowaty PA. 2017. Choosy males in Jamaican field crickets. Animal Behaviour 133: 101-108.

Bonduriansky R. 2001. The evolution of male mate choice in insects: a synthesis of ideas and evidence. Biological Reviews 76: 305-339.

Bonduriansky R, Rowe L. 2003. Interactions among mechanisms of sexual selection on male body size and head shape in a sexually dimorphic fly. International Journal of Organic Evolution 57: 2046-2053.

Brusatte SL, Sakamoto M, Montanari S, Harcourt-Smith WEH. 2012. The evolution of cranial form and function in theropod dinosaurs: insights from geometric morphometrics. Journal of Evolutionary Biology 25: 365-377.

Bussiere LF, Gwynne DT, Brooks R. 2008. Contrasting sexual selection on males and females in a role-reversed swarming dance fly Rhamphomyia longicauda Loew (Diptera: Empididae). Journal of Evolutionary Biology 21: 1683-1691.

Carey CJ, Bull CM. 1986. Recognition of mates in the Portuguese millipede Ommatoiulus moreletii. Australian Journal of Zoology 34: 837-842.

Carvajal-Rodriguez A, Rolan-Alvarez E. 2006. JMATING: A software for the analysis of sexual selection and sexual isolation effects from mating frequency data. $B M C$ Evolutionary Biology 6: 40. Available at http://acraaj.webs. uvigo.es/JMsoft.htm

Cator LJ, Zanti Z 2016. Size, sounds and sex: interactions between body size and harmonic convergence signals determine mating success in Aedes aegypti. Parasite Vectors 9: 622. doi: 10.1186/s13071-016-1914-6.

Changbunjong T, Sumruayphol S, Weluwanarak T, Ruangsittichai J, Dujardin JP. 2016. Landmark and outlinebased geometric morphometrics analysis of three Stomoxys flies (Diptera: Muscidae). Folia Parasitologica 63: 037.

Cheng L-I, Howard RW, Campbell JF, Charlton RE, Nechols JR, Ramaswamy SB. 2004. Mating behavior of Cephalonomia tarsalis (Ashmead) (Hymenoptera: Bethylidae) and the effect of female mating frequency on offspring production. Journal of Insect Behaviour 17: 227-245.

Cooke SB, Terhune CE. 2015. Form, function, and geometric morphometrics. The Anatomical Record 298: 5-28.

Cooper MI. 2015. Competiton affected by re-mating interval in a myriapod. Journal of Entomology and Zoology Studies 3: 77-78. 
Cooper MI. 2016. Post-insemination associations between males and females in Diplopoda: A remark on Alcock's (1994) predictions of the mate-guarding hypothesis. Journal of Entomology and Zoology Studies 4: 283-285.

Cooper MI. 2017. The affect of female body width on copulation duration in Centrobolus inscriptus (Attems). Journal of Entomology and Zoology Studies 5: 732-733.

Cooper MI, Telford SR. 2000. Copulatory sequences and sexual struggles in millipedes. Journal of Insect Behavior 13: 217 230 .

Córdoba-Aguilar A, Uhía E, Cordero Rivera A. 2003. Sperm competiton in Odonata (Insecta): The evolution of female sperm storage and rivals` sperm displacement. Journal of Zoology 261: 381-398.

Danielsson I. 2001. Antagonistic pre- and post-copulatory sexual selection on male body size in a water strider Gerris lacustris. Proceedings of the Royal Society of London B: Biological Sciences 268: 77-81.

Darwin C. 1871. The descent of man and selection in relation to sex. John Murray, London, UK.

Dickinson J. 1997. Multiple mating, sperm competition, and cryptic female choice in the leaf beetles (Coleoptera: Chrysomelidae). Pp. 164-183 in: Choe JC, Crespi BJ eds., The Evolution of Mating Systems in Insects and Arachnids. Cambridge University Press, Cambridge.

Dougherty LR, Shuker DM. 2014. Precopulatory sexual selection in the seed bug Lygaeus equestris: a comparison of choice and no-choice paradigms. Animal Behaviour 89: 207-214.

Eberhard WG. 1996. Female control: sexual selection by cryptic female choice. Princeton University Press, Princeton, New Jersey.

Edward DA. 2015. The description of mate choice. Behavioral Ecology 26: 301-310.

Edward DA, Chapman T. 2011. The evolution and significance of male mate choice. Trends in Ecology and Evolution 26: 647-654.

Enghoff HE. 1985. The millipede family Nemasomatidae. With description of a new genus, and a revision of Orinisobates (Diplopoda: Julida). Entomologica Scandinavica 15: 27-67.

Enghoff HE. 1992a. Dolichoiulus - a mostly Macaronesian multitude of millipedes. With the description of a related new genus from Tenerife, Canary Islands (Diplopoda, Julida, Julidae). Entomologica Scandinavica Supplements 40: $1-158$.

Enghoff HE. 1992b. The size of a millipede. Berichte des Naturwissenschaftlich-medizinischen Vereins in Innsbruck Supplement 10: S47-S56.

Garga N, Proctor H, Belczewski R. 1997. Leg size affects male mating success in Tarsonemus confusus Ewing (Prostigmata: Tarsonemidae). Acarologia 38: 369-375.

Gasparini C, Pilastro A, Evans JP. 2011. Male genital morphology and its influence on female mating preferences and paternity success in guppies. Plos ONE 6: e22329.

Haacker U. 1968. Stridulation bei Loboglomeris (Diplopoda). Die Naturwissenschaften 55: 656-657.

Haacker U. 1969. An attractive secretion in the mating behaviour of a millipede. Zeitschrift für Tierpsychologie 26: 988-990.

Haacker U, Fuchs S. 1970. Das Paarungsverhalten von Cylindroiulus punctatus Leach. Zeitschrift fur Tierpshychologie 27: 641-648.
Hagler JR, Jackson CG. 2001. Methods for marking insects: current techniques and future prospects. Annual Review of Entomology 46: 511-543.

Harari AR, Landolt PJ, O`Brien CW, Brockmann HJ. 2003. Prolonged mate guarding and sperm competition in the weevil Diaprepes abbreviatus (L.). Behavioural Ecology 14: 89-96.

Head ML, Kozak GM, Boughman JW. 2013. Female mate preferences for male body size and shape promote sexual isolation in threespine sticklebacks. Ecology and Evolution 3: 2183-2196. DOI: 10.1002/ece3.631.

Heath J, Bocock KL, Mountford MD. 1974. The life history of the millipede Glomeris marginata (Villers) in north-west England. Symposia of the Zoological Society of London 32: 433-462.

Herberstein ME, Schneider JM, Uhl G, Michalik P. 2011. Sperm dynamics in spiders. Behavioral Ecology 22: 692-695.

Honěk A. 1993. Intraspecific variation in body size and fecundity in insects: A general relationship. Oikos 66: 483-492.

Hopkin SP, Read HJ. 1992. The biology of millipedes. Oxford University Press, Oxford.

Ilić BS, Mitić BM, Makarov SE. 2016. Sexual dimorphism in Apfelbeckia insculpta (L. Koch, 1867) (Myriapoda: Diplopoda: Callipodida). Archives of Biological Sciences 69: 23-33.

Jimenez-Perez A, Wang Q. 2004. Sexual selection in Cnephasia jactatana (Lepidoptera: Tortricidae) in relation to age, virginity, and body size. Annals of the Entomological Society of America 97: 819-824.

Jones AG, Ratterman NL. 2009. Mate choice and sexual selection: What have we learned since Darwin? Proceeding of the National Academy of Sciences of the United States of America 106: S1 10001-S1 10008.

Jovanović Z, Pavković-Lučić S, Ilić B, Vujić V, Dudić B, Makarov S, Lučić L, Tomić V. 2017. Mating behaviour and its relationship with morphological features in the millipede Pachyiulus hungaricus (Karsch, 1881) (Myriapoda, Diplopoda, Julida). Turkish Journal of Zoology 41: 10101023.

Kahn AT, Mautz B, Jennions MD. 2010. Females prefer to associate with males with longer intromittent organs in mosquitofish. Biology Letters 6: 55-58.

Kaliontzopoulou A, Carretero MA, Llorente GA. 2007. Multivariate and geometric morphometrics in the analysis of sexual dimorphism variation in Podarcis lizards. Journal of Morphology 268: 152-165.

Kamimura Y. 2000. Possible removal of rival sperm by the elongated genitalia of the earwig, Euborellia plebeja. Zoological Science 17: 667-672.

Kamimura Y. 2014. Pre- and postcopulatory sexual selection and the evolution of sexually dimorphic traits in earwigs (Dermaptera). Entomological Science 17: 139-166.

Kelly CD. 2014. Sexual selection, phenotypic variation, and allometry in genitalic and non-genitalic traits in the sexually size-dimorphic stick insect Micrarchus hystriculeus. Biological Journal of the Linnean Society 113: 471-484.

Klingenberg CP. 2011. MorphoJ: an integrated software package for geometric morphometrics. Molecular Ecology Resources 11: 353-357. Available at http://www.flywings. org.uk/morphoj_page.htm

Langerhans RB, Layman CA, DeWitt TJ. 2005. Male genital 
size reflects a tradeoff between attracting mates and avoiding predators in two live-bearing fish species. Proceedings of the National Academy of Sciences of the United States of America 102: 7618-7623.

Lazányi E, Vagalinski B. 2013. Redefinition of the millipede subgenus Megaphyllum sensu stricto Verhoeff, 1894 and neotype designation for Megaphyllum austriacum (Latzel, 1884) (Myriapoda: Diplopoda: Julida: Julidae). Zootaxa 3741: 55-100.

Lazányi E, Vagalinski B, Korsos Z. 2012. The millipede genus Megaphyllum Verhoeff, 1894 in the Balkan Peninsula, with description of new species (Myriapoda: Diplopoda: Julida: Julidae). Zootaxa 3228: 1-47.

LeVasseur-Viens H, Moehring AJ. 2014 Individual genetic contributions to genital shape variation between Drosophila simulans and D. mauritiana. International Journal of Evolutionary Biology Article ID 808247: 9 pages. DOI: $10.1155 / 2014 / 808247$

Levitan DR. 2004. Density-dependent sexual selection in external fertilizers: variances in male and female fertilization success along the continuum from sperm limitation to sexual conflict in the sea urchin Strongylocentrotus franciscanus. The American Naturalist 164: 289-309.

Lu W, Wang Q, Tian M, Xu J, Lv J, Qin A. 2013. Mating behavior and sexual election in a polygamous beetle. Current Zoology 59: 257-264.

Makarov SE, Ćurčić BPM, Tomić VT, Legakis A. 2004. The Diplopods of Serbia, Montenegro, and the Republic of Macedonia. Monographs. Volume IX. Belgrade - Athens, Institute of Zoology - Faculty of Biology - University of Belgrade; Hellenic Zoological Society, Committee for Karst and Speleology; Serbian Academy of Sciences and Arts.

Mathews PL, Bultman TL. 1993. Mating behaviour of a parajulid millipede, Aniulus bollmani. Canadian Journal of Zoology 71: 2297-2300.

McPeek MA, Shen L, Torrey JZ, Farid H. 2008. The tempo and mode of three-dimensional morphological evolution in male reproductive structures. The American Naturalist 171: E158178.

McPeek MA, Shen L, Farid H. 2009. The correlated evolution of three-dimensional reproductive structures between male and female damselflies. Evolution 63: 73-83.

Menezes BF, Vigoder FM, Peixoto AA, Varaldi J, Bitner-Mathé BC. 2013. The influence of male wing shape on mating success in Drosophila melanogaster. Animal Behaviour 85: 1217-1223.

Minelli A, Michalik P. 2015. Diplopoda: Reproduction. Pp. 237265 in: Minelli A ed., The Myriapoda. Volume 2. Brill, Leiden.

Møller AP; Zamora-Muñoz C. 1997. Antennal asymmetry and sexual selection in a cerambycid beetle. Animal Behaviour 54: $1509-1515$.

Outomuro D, Söderquist L, Nilsson-Örtman V, Cortázar-Chinarro M, Lundgren C, Johansson F. 2016. Antagonistic natural and sexual selection on wing shape in a scrambling damselfly. Evolution 70: 1582-1595.

Pavković-Lučić S, Kekić V. 2009. Influence of mating experience on mating latency and copulation duration in Drosophila melanogaster females. Russian Journal of Genetics 45: 875-877.

Pavković-Lučić S, Kekić V, Čvoro A. 2009. Larger male mating advantage depends on sex ratio in Drosophila melanogaster. Ethology, Ecology and Evolution 21: 155-160.

Polihronakis M. 2006. Morphometric analysis of intraspecific shape variation in male and female genitalia of Phyllophaga hirticula (Coleoptera: Scarabeidae: Melolonthidae). Annals of the Entomological Society of America 99: 144-150.

Ponlawat A, Harrington L. 2009. Factors associated with male mating success of the dengue vector mosquito, Aedes aegypti. The American Journal of Tropical Medicine and Hygiene 80: 395-400.

R Development Core Team. 2013. Version 3.0.2. The R Project for Statistical Computing, Vienna, Austria. Available at http:// www.r-project.org/

Richmond MP. 2014. The role of aedeagus size and shape in failed mating interactions among recently diverged taxa in the Drosophila mojavensis species cluster. BMC Evolutionary Biology 14: 255.

Rodriguero MS, Vilardi JC, Vera MT, Cayol JP, Rial E. 2002. Morphometric traits and sexual selection in medfly (Diptera: Tephritidae) under field cage conditions. Florida Entomologist 85: 143-149.

Rohlf FJ. 2008. TpsDig, Version 2.12. Stony Brook, NY, USA: SUNY at Stony Brook. Available at http://life.bio.sunysb.edu/ morph/soft-dataacq.html.

Rolán-Alvarez E, Caballero A. 2000. Estimating sexual selection and sexual isolation effects from mating frequencies. Evolution 54: 30-36.

Rowe M. 2010. Copulation mating system and sexual dimorphism in an Australian millipede, Cladethosoma clarum. Australian Journal of Zoology 58: 127-132.

Rowe L, Arnqvist G. 2012. Sexual selection and the evolution of genital shape and complexity in water striders. Evolution 66 : 40-54. DOI: 10.1111/j.1558-5646.2011.01411.x

Sasakawa K. 2016. Utility of geometric morphometrics for inferring feeding habit from mouthpart morphology in insects: tests with larval Carabidae (Insecta: Coleoptera). Biological Journal of the Linnean Society 118: 394-409.

Schneider JM, Gilberg S, Frohmage L, Uhl G. 2006. Sexual conflict over copulation duration in a cannibalistic spider. Animal Behaviour 71: 781-788.

Schöfl G, Taborsky M. 2002. Prolonged tandem formation in firebugs (Pyrrhocoris apterus) serves mate-guarding. Behavioral Ecology and Sociobiology 52: 426-433. DOI: 10.1007/s00265-002- 0524-9.

Sheets HD. 2003. IMP-Integrated Morphometrics Package. Buffalo: Department of Physics, Canisius College. Available at http://www3 .canisius.edu/ sheets/IMP\%208.htm

Sillén-Tullberg B. 1981. Prolonged copulation: A male 'postcopulatory' strategy in a promiscuous species, Lygaeus equestris (Heteroptera: Lygaeidae). Behavioral Ecology and Sociobiology 9: 283-289. DOI: 10.1007/BF00299884.

Simmons LW. 2001. Sperm competition and its evolutionary consequences in insects. Princeton University Press, Princeton, New Jersey.

Simmons LW. 2014. Sexual selection and genital evolution. Austral Entomology, 53: 1-17.

Stuart-Smith J, Swain R, Wapstra E. 2007. The role of body size in competition and mate choice in an agamid with femalebiased size dimorphism. Behaviour 144: 1087-1102.

Sturm R. 2016. Relationship between body size and reproductive capacity in females of the black field cricket (Orthoptera, 
Gryllidae). Linzer Biologische Beiträge 48: 1823-1834.

Sugano YC, Sasaki Y, Akimoto S.-I. 2008. Effects of body size and shape on mating frequency in the brachypterous grasshopper Podisma sapporensis. Journal of Orthoptera Research 17: 243-248.

Tadler A. 1996. Functional morphology of genitalia of four species of julidan millipedes (Diplopoda: Nemasomatidae; Julidae). Zoological Journal of the Linnean Society 118: 83-97.

Telford SR, Dangerfield JM. 1990. Manipulation of the sex ratio and duration of copulation in the tropical millipede Alloporus uncinatus: A test of the copulatory guarding hypothesis. Animal Behaviour 40: 984-986.

Telford SR, Dangerfield JM. 1993a. Mating tactics in the tropical millipede Alloporus uncinatus (Diplopoda: Spirostreptidae). Behaviour 124: 45-56.

Telford SR, Dangerfield JM. 1993b. Mating behaviour and mate choice experiments in some tropical millipedes (Diplopoda: Spirostreptidae). South African Journal of Zoology 28: 155160.

Terzić T, Anđelković M, Stamenković-Radak M. 1994. Effect of fluorescent dust, as a marker, on the frequency of mating in Drosophila melanogaster. Drosophila Information Service 75: 164-165.

Trajković J, Pavković-Lučić S, Savić T. 2013. Mating success and wing morphometry in Drosophila melanogaster after long-term rearing on different diets. Behaviour 150: 14311448.

Tregenza T, Hosken DJ. 2005. Mate choice: Been there, done that. Current Biology 15: R959-R961.

Wesener T, Köhler J, Fuchs S, van den Spiegel D. 2011. How to uncoil your partner-"mating songs" in giant pill-millipedes (Diplopoda: Sphaerotheriida). Naturwissenschaften 98: 967-975.

Willemart RH, Osses F, Chelini MC, Macias-Ordonez R, Machado G. 2009. Sexually dimorphic legs in a neotropical harvestman (Arachnida, Opiliones): Ornament or weapon? Behavioural Processes 80: 51-59.
Wojcieszek JM, Simmons LW. 2011. Male genital morphology influences paternity success in the millipede Antichiropus variabilis. Behavioral Ecology and Sociobiology 65: 18431856.

Wojcieszek JM, Austin P, Harvey MS, Simmons LW. 2012. Micro-CT scanning provides insight into the functional morphology of millipede genitalia. Journal of Zoology 287: 91-95.

$\mathrm{Xu} \mathrm{J}$, Wang Q. 2010a. Form and nature of premating sexual selection in both sexes of a moth. Naturwissenschaften 97 : 617-625.

Xu J, Wang Q. 2010b. Mechanisms of last male precedence in a moth: Sperm displacement at ejaculation and storage sites. Behavioral Ecology 21: 714-721.

Yang L, Wang Q. 2004. Precopulation sexual selection in Nysius huttoni White (Heteroptera: Lygaeidae) in relation to morphometric traits. Journal of Insect Behavior 17: 695707.

Zelditch ML, Swiderski D, Sheets D, Fink WL. 2004. Geometric morphometrics for biologists: a primer. Elsevier, London.

Zhou Z-S, Guo J-Y, Guo W, Zheng H-Y, Wan, F-H. 2012. Effects of morphological traits, age, and copulation experience on mate choice in Ophraella communa. Biocontrol Science and Technology 22: 81-91.

Received: 7 March 2018

Revised and accepted: 22 May 2018

Published online: 19 September 2018

Editor: A. Minelli 